\title{
The Economics, Opportunities, and Challenges of Health Insurance Exchanges
}

\section{MARK DUGGAN AND BOB KOCHER}

A central component of the Affordable Care Act (ACA) is the creation of state-based health insurance exchanges, which have the potential to substantially improve the functioning and expand the reach of the private health insurance market. Here, we describe salient features of the current market for health insurance and explain how the exchanges will build on this system by altering incentives for individuals, employers, and

Mark Duggan is Professor of Economics at the University of Maryland, a Research Associate at the National Bureau of Economic Research, and former Senior Economist for Health Care Policy, Council of Economics Advisors. Bob Kocher, MD, is Director of the McKinsey Center for U.S. Health System Reform, a Non-Resident Senior Fellow, Brookings Institution, and former Special Assistant to the President for Health Care and Economic Policy, National Economic Council. insurers. We conclude with a discussion of the challenges and key issues that remain.

THE PRIVATE HEALTH INSURANCE MARKET

The U.S. private health insurance market 1 has been dominated by employer-sponsored insurance (ESI). In 2009, more than 90 percent of the 172 million non-elderly individuals with private health insurance obtained it through their, or a family member's, employer (U.S. Census Bureau, 2010). The dominance of ESI is due to the tax subsidy for employer-provided health insurance, the benefits of pooling together many individuals when negotiating contracts with health insurers, and other factors.

The system, however, works relatively poorly for employees of small firms. Small firms are much less likely to offer insurance, are likely to offer fewer plan options when they do, and must pay up to 18 percent more than their larger counterparts for the same policy. While 98 percent of firms with 200 or more employees offered ESI to their workers in 2009, just 46 percent of firms with 3-9 employees did (Kaiser Family Foundation, 2009). As a result, employees of small firms (and their dependents) are significantly more likely than workers at large firms to lack health insurance. The problems are similar for the selfemployed, and even more pronounced for those who are not working.

Individuals without ESI coverage can buy private health insurance on the individual market, though without the tax subsidy ESI enjoys. Partly because of the resulting higher (net) prices, individual policies tend to be much less comprehensive than ESI policies. Additionally, individuals with existing health problems 
often find it difficult or impossible to obtain coverage at affordable rates. Moreover, it is difficult for individuals to conduct apples-toapples comparisons of the price and quality of available plan options. Partly because of this, the individual market is thin, insuring just 6 percent of non-elderly individuals in 2009.

From 1999 to 2009, average ESI premiums increased by 70 percent in real terms, while median household income (which excludes employer contributions for ESI) actually declined by 5 percent. Largely because of this contrast, private health insurance coverage fell to 65 percent of the non-elderly population, versus what had been 74 percent ten years earlier

\section{THE EXCHANGES}

The ACA will increase health insurance cov1 erage beginning in January 2014, through two channels: First, Medicaid eligibility will be extended to individuals with incomes up to 133 percent of the federal poverty line (FPL). While current income thresholds for Medicaid eligibility vary widely across states, this is an expansion for almost all states. For example, 40 states currently have Medicaid eligibility thresholds below 133 percent of FPL for lowincome parents, with the median state having a threshold of 64 percent and the lowest (Arkansas), just 17 percent. Eligibility standards are even tighter for childless adults, with just six states providing any Medicaid coverage for this group (KFF, 2009).

Second, the creation of state-based health insurance exchanges will allow individuals to select from qualified health plans operating in their area of residence. By 2019, the new rules will raise Medicaid enrollment by 16 million, and the exchanges will cover an additional 24 million people. When these changes are combined with an expected eight-million-person decline in the number of people with other sources of private coverage, the ACA will reduce the number of uninsured people by a total of 32 million (CBO, 2010).

Individuals without an affordable ESI offer will be able to acquire coverage through the exchanges, with subsidies that decline with income available for households with incomes between 133 percent and 400 percent of FPL. The subsidies are structured so that individuals with higher incomes receive smaller subsidies. (For example, a family of four with a 2014 income of $\$ 45,000$ receives a subsidy of $\$ 9,500$ to purchase a $\$ 12,100$ family policy, while a similar family with income of $\$ 90,000$ would receive approximately $\$ 3,600$.) Additionally, firms with up to 100 workers will be able to acquire coverage for their workers through the exchanges, although their workers would not be eligible for the premium subsidies.

The ACA requires states to set up exchanges by January 2014, but gives them considerable latitude as to structure. A state can set up one exchange that serves both individuals and small employers, or segment these markets with separate exchanges. Similarly, states can join together to form regional exchanges, which are likely to be relatively attractive to states with low populations, in order to stabilize risk pools and premium fluctuations. Perhaps most noteworthy, beginning in 2017, states can allow firms with more than 100 workers to acquire coverage for their workers through the exchanges.

\section{KEY FUNCTIONS OF THE EXCHANGES}

In practice, state exchanges will have five 1 primary functions:

The Economists' Voice December, 2010

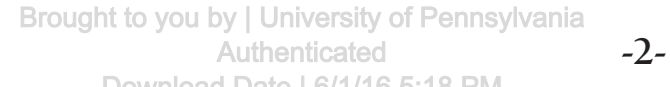

Download Date | 6/1/16 5:18 PM

\section{$-$}


1. Determine which plans can be offered

2. Assist consumers in choosing between plans based on price and quality

3. Determine subsidies for which individuals are eligible, and calculate net premiums

4. Minimize incentives for plans to preferentially target particular segments of individuals and employers

5. Perform risk-adjustments to mitigate plans' cherry-picking profitable consumers

How exchanges operationalize these functions will largely determine how successfully the exchange market functions. Implementing each function will require skillful tradeoffs. For example, effective competition and shopping can be achieved by having several plan options without overwhelming consumers with choice. Today, most individuals and small groups do not have sufficient choice to enable effective shopping. On the opposite extreme, many workers in the Federal Employee Health Program have too many choices, leading to the majority of workers' aggregating to a single plan, and resulting in ineffective competition since the FEHBP program does not give consumers adequate information to clarify the trade-offs across plans.
If exchanges commoditize plan-offering to enable simple price-comparison shopping for consumers, the result could be exchanges precluding plans from offering innovative benefit designs-such as narrow provider networks, and large incentives for preventive care-that are important approaches for constraining premium growth. When it comes to subsidydetermination, the frequency with which income data are updated (e.g., quarterly, annually) will affect the inevitable shifting of people between Medicaid and the exchange, and will affect future tax obligations for those whose incomes increase (and thus, whose subsidies decrease) mid-year.

Additionally, there is the question of how effectively exchanges reduce distortions resulting from premiums that are constrained by rating rules that limit variation to 3:1 based on age, with adjustments only for smoking status. The level of effectiveness here will be critical in assuring competition across the entirety of the exchange. Certain groups, such as young people who smoke, could be disproportionately profitable, since they will have high premiums relative to their expected costs. In contrast, older non-smokers may have artificially low premiums and could be unprofitable. Additionally, exchanges will have to risk-adjust plan payments, so that plans attracting a disproportionate share of sicker patients will not be penalized. However, the federal government's recent experience with payments to Medicare Advantage plans suggests that this will be very difficult.

\section{ECONOMIC BENEFITS OF THE EXCHANGES}

— ffective exchanges will bring millions of people into the market for private health insurance through the mandate and the sliding-scale subsidies. For small businesses, one major benefit of exchanges could be disintermediating brokers and their commissionswhich can equal as much as $10 \%$ of the premium. Moreover, small businesses gain far greater premium stability by being a part of a larger risk pool with the new rating rules.

Also, the exchanges will provide a powerful incentive for insurers to price competitively, since individuals will bear the full cost on the margin of more generous plans. In contrast, workers who purchase insurance through employers today are shielded from the full marginal cost, partly because of the tax 
exclusion. In response, plans are likely to innovate in ways that reduce premium growth by increasing the productivity of their provider networks and the effectiveness of medicalmanagement programs—not just by trying to drive unit prices down.

\section{POTENTIAL WEAKNESSES OF THE EXCHANGES}

To deliver the consumer and economic ben-

1 efits of exchanges, operators must overcome two potential policy shortcomings: First, setting exchanges at the level of the State was largely a political choice, not an economic one. While this choice allows States flexibility to tailor plan choices to the needs of their residents-perhaps fostering new entrants, and allowing local plans to participate-it makes it far harder to achieve scale and consistency for key functions. Moreover, it significantly complicates preparations for the 2014 launch. (Simply getting IT systems for subsidy determination and Medicaid eligibility to work in each state will be a major accomplishment, let alone constructing a risk-adjustment algorithm and determining how many plans are eligible.)
Since many states have small populations, risk pools will be less stable there, leading to greater premium volatility and, if premiums rise more than anticipated, greater subsidy cost.

A second major potential weakness of the ACA is that it requires separate individual and small-employer exchanges-which amplifies the volatility of small risk pools and leads to potentially higher premiums. If premiums rise, the problem could spiral, as employers with younger and healthier workforces forgo exchanges, since they are able to obtain cheaper insurance elsewhere.

The individual market outside of exchanges is likely to wither over time, since individual subsidies can only be accessed in the exchange. In contrast, the small-group market could persist for a long time. Bifurcated markets will make avoiding adverse selection in exchanges difficult. This was the unfortunate outcome for most prior exchanges targeting businesses-most recently, the exchange run by the Pacific Business Group on Health. Also, more employers may drop coverage, since purchasing as an employer brings no benefits to a worker who can buy cheaper subsidized insurance on the individual exchange. This is particularly true for small firms that incur no penalty if they drop coverage. If this scenario becomes reality, or if the individual exchange proves to be a lower-cost and more efficient market, then the problem of employers' dropping coverage could be much worse than the $\mathrm{CBO}$ forecast predicts.

\section{KEY ISSUES/CHALLENGES FOR THE EXCHANGES}

The exchanges must overcome two major I near-term challenges: First, the consumer experience has to work well, if the ACA is to fulfill its intention of bringing in millions of uninsured (and particularly, young and healthy) individuals. Subsidies must be accurate. Real-time shopping experiences must be intuitive and quick. Interactions should be personalized over time by medical statuses and preferences. Many private-sector firms, but few in the public sector (think of state Medicaid offices or DMVs), have shown they can deliver such experiences. Yet poor service could lead to low uptake and adverse selection. Here, well-designed sites like healthcare.gov offer glimmers of hope, and much can be learned 
from examples such as the Part D plan-finder and the Massachusetts Connector.

Second, risk-adjustment and product standards need to ensure that individuals in all segments of the market receive attractive insurance options. It would be unfortunate if exchanges were to give plans an incentive to target profitable young smokers at the expense of older and sicker individuals. The tools of branding, marketing, and product design give plans a big advantage over current risk-adjustment approaches. There is little time to develop better approaches and the ACA only calls for prospective-not retrospective-risk adjustment. A vibrant market develops across all segments in the exchange only if each offers profit potential. To achieve this, exchanges will have to get riskadjustment to work as effectively as possible, and achieve the proper balance between innovative benefit-designs and standardized plans.

\section{CONCLUSION}

工 ow well exchanges operationalize their 1 five key functions and how effectively they overcome these challenges will likely determine whether Americans perceive the ACA as beneficial, and what will be the long-term role for exchanges as a public-policy solution. If exchanges execute their primary functions skillfully and arrive at effective solutions to these challenges, the benefits to consumers and employers will be substantial: Exchanges could serve as a catalyst that drives down premium growth, as plans seek to attract larger shares of increasingly value-conscious consumers. Moreover, by reducing distribution costs and shifting the basis of competition from underwriting to medical value, exchanges could be an instigator of significant productivity among plans and the health care sector.

Time will tell if exchanges live up to their promise. To do so will require exceptional leadership at the state level, timely federal policy, sufficient funding, and enough political inoculation to make the economic tradeoffs that are necessary.

Letters commenting on this piece or others may be submitted at submit.cgi? context $=e v$.

REFERENCES AND FURTHER READING

Congressional Budget Office (2010) "H.R. 4872, Reconciliation Act of 2010 (Final Health
Care Legislation)," Cost estimate for the amendment in the nature of a substitute for H.R. 4872, incorporating a proposed manager's amendment made public on March 20, 2010.

http://www.cbo.gov/doc.cfm?index=11379.

Kaiser Family Foundation (KFF) and Health Research and Educational Trust (2009) "Employer Health Benefits: 2009 Annual Survey." Avilable at: http://ehbs.kff.org/pdf/2009/7936. pdf.

U.S. Census Bureau (2010) "Income, Poverty, and Health Insurance Coverage in the United States: 2009." http://www.census. gov/prod/2009pubs/p60-236.pdf.

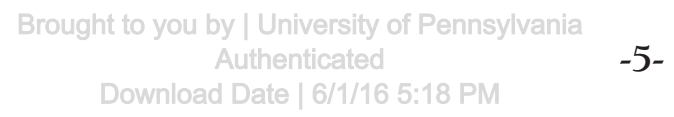

